\title{
Sintomatologia e filosofia da afirmação em Nietzsche
}

\author{
Eder Corbanezi*,**
}

\begin{abstract}
Resumo: Estabelecida em Assim falava Zaratustra, a associação dos conceitos de vida, valor e vontade de potência se revela rica em consequências para o pensamento de Nietzsche. Nosso objetivo é investigar como essas noções operam na sintomatologia nietzschiana, procedimento que consiste em avaliar o valor dos valores, tomandoos como sinais de vida ascendente ou decadente. Esperamos mostrar que um modo de estimar valores só é considerado superior se traduz uma afirmação da concepção nietzschiana de vida ascendente. Por fim, contamos sustentar que esse critério para avaliar o valor dos valores implica, ele mesmo, valores, o que o torna injusto.
\end{abstract}

Palavras-chave: sintomatologia, vida, vontade de potência, valor, critério.

\footnotetext{
* Doutorando em cotutela pela Universidade de São Paulo (USP), São Paulo, SP, Brasil e pela **Université Paris 1 Panthéon-Sorbonne, Paris, França.

ORCID https://orcid.org/0000-0001-7916-5788

Correio eletrônico: edercorbanezi@hotmail.com
} 
Corbanezi, E.

I.

Em escritos anteriores a Assim falava Zaratustra, Nietzsche já havia associado os conceitos de vida e de avaliação ${ }^{1}$, assim como já se tinha servido da noção de potência para meditar sobre diversas dimensões da vida ${ }^{2}$. Mas é nesse escrito que, em sua obra publicada, o autor estabelece de maneira explícita uma relação intrínseca entre as noções de vida, de valor e de vontade de potência: viver, sustenta ele, consiste em estimar valores, e toda estimativa de valor, por sua vez, traduz o exercer-se de vontades de potência ${ }^{3}$. Resultado de reflexões precedentes, esse vínculo conceitual instaurado em Assim falava Zaratustra se revela decisivo para o pensamento posterior de Nietzsche.

É precisamente uma das consequências de tal vínculo que nos propomos a investigar: trata-se de examinar o papel desempenhado pela associação das noções de vida, de valor e de vontade de potência na sintomatologia nietzschiana. $\mathrm{O}$ objetivo é mostrar como essa

1 No parágrafo 32 de Humano, demasiado humano, por exemplo, Nietzsche sustenta que é impossível viver sem avaliar. Nesse texto, para designar a ação de avaliar, ele utiliza o verbo abschätzen, além dos substantivos Abschätzung e Schätzung (MA I/HH I 32, KSA 2.51-52). O autor ainda não recorre, em nenhuma página do livro, à noção de Werthschätzung, que será empregada, entretanto, no Prefácio redigido em 1886 para a segunda edição da obra (MA I/HH I, Prefácio, 1 e 6, KSA 2.13 e 20).

2 Num fragmento póstumo dos anos 1870, assegura Nietzsche: "O elemento principal da ambição é chegar ao sentimento de sua potência. [...] Medo (negativamente) e vontade de potência (positivamente) explicam nossa grande consideração quanto às opiniões das pessoas. [...] 0 prazer da potência explicase pelo desprazer da dependência, da impotência, experimentado uma centena de vezes" (Nachlass/ FP 1876-1877, 23[63], KSA 8.425). Em Aurora, Nietzsche reflete sobre a grande política apoiando-se na ideia de "sentimento de potência [Machtgefuihl]". Nesse texto, a noção de "sentimento da potência [Gefiihle der Macht]" intervém igualmente em sua análise do sentimento e da denominação dos valores "bom" e "mau", conforme diferentes perspectivas: "Quando o homem está com o sentimento da potência, ele se percebe como bom e assim se denomina: e precisamente então os outros, nos quais ele deve descarregar sua potência, percebem-no como mau e assim o chamam!" (M/A 189, KSA 3.161-162, trad. PCS modificada). Para as citações da obra de Nietzsche, utilizamos as traduções de Rubens Rodrigues Torres Filho (RRTF) e de Paulo César de Souza (PCS). Quando não há indicação, a tradução é de nossa responsabilidade.

3 Cf. ZA/ZA I, Dos mil e um alvos, KSA 4.74-76, e ZA/ZA II, Da superação de si, KSA 4.146-149, trad. RRTF.

34 | Cad. Nietzsche, Guarulhos/Porto Seguro, v.40, n.2, p. 33-51, maio/agosto, 2019. 
sintomatologia constitui um procedimento destinado a avaliar e a hierarquizar as avaliações, identificando se elas são sinais de uma vida ascendente ou de uma vida decadente. A partir dessa análise, esperamos defender a ideia de que a filosofia da afirmação cumpre uma função decisiva no mencionado procedimento sintomatológico, já que um modo de estimar valores só é qualificado como ascendente e superior se ele traduz uma afirmação - e não uma negação - da vida, ou melhor, da concepção nietzschiana de vida ascendente.

\section{II.}

No capítulo intitulado Dos mil e um alvos, da primeira parte de Assim falava Zaratustra, Nietzsche sustenta que a conservação e os triunfos de cada povo se explicam não tanto na medida em que cada comunidade avalie pura e simplesmente, mas sobretudo na medida em que cada comunidade avalie de modo particular: enquanto condição necessária da conservação e dos triunfos de determinado povo, seus valores - o que ele estima bom ou ruim - não coincidem com os valores de outros povos. As avaliações instituídas por cada comunidade, acrescenta Nietzsche, não lhes caíram "como uma voz do céu" (ZA/ZA I, Dos mil e um alvos, KSA 4.75, trad. RRTF): ao contrário, elas exprimem antes "a voz de sua vontade de potência" (ZA/ZA I, Dos mil e um alvos, KSA 4.74, trad. PCS modificada). Enfim, observa o filósofo, os valores não são encontrados, mas sim introduzidos nas coisas pelos homens, "para se conservar" (ZA/ZA I, Dos mil e um alvos, KSA 4.75, trad. RRTF).

O capítulo Da superação de si, presente na segunda parte de Assim falava Zaratustra, retoma aquela associação entre as noções de vida, de valor e de vontade de potência; dessa relação, porém, sublinham-se ali outros aspectos. Se as noções de vida e de avaliação reenviam igualmente ao conceito de vontade de potência, enfatizase agora não a possibilidade de conservar-se pela instituição de 
Corbanezi, E.

valores, mas sim o risco de perecimento que acarretam determinadas avaliações: "Muito, para o vivente, é estimado [geschätzt] mais alto do que o próprio viver" (ZA/ZA II, Da superação de si, KSA 4.149, trad. RRTF), escreve Nietzsche, destacando circunstâncias em que "a vida se sacrifica - por potência" (ZA/ZA II, Da superação de si, KSA 4.148, trad. PCS modificada).

Esses dois capítulos de Assim falava Zaratustra indicam, assim, que as avaliações podem desempenhar dois papeis opostos em relação à vida: o de condição de conservação e de vitórias ou o de fator de declínio e de perecimento. À luz de fragmentos póstumos contemporâneos do livro em tela, assim como sob o prisma de escritos ulteriores, examinaremos a seguir esse duplo papel das avaliações em relação à vida e as suas consequências para a sintomatologia nietzschiana.

\section{III.}

Se o próprio viver consiste, segundo Nietzsche, em "estimar valores [das Werthschätzen]" (Nachlass/FP 1882-1883, 5[1] 234, KSA 10.214) $)^{4}$, comecemos por perguntar sobre a maneira pela qual as estimativas de valor se formam e sobre o modo pelo qual elas se relacionam com a vida. É preciso notar, logo de início, que os valores não são dados de antemão, para serem simplesmente descobertos; tampouco são eles algo absoluto, universal e eterno. Os valores são, ao contrário, necessariamente constituídos a partir de estimativas: "Somente pelo estimar [das Schätzen] há valor [Werth]" (ZA/ZA I, Dos mil e um alvos, KSA 4.75, trad. RRTF). E toda estimativa de valor (Werthschätzung) é relativa a uma determinada perspectiva e a um determinado modo de interpretar. $\mathrm{O}$ conceito de interpretação faz ver que toda estimativa de valor implica necessariamente um

4 Ver também o Nachlass/FP 1883, 12[9], KSA 10.401, em que Nietzsche exclama: “A vida mesma não é - estimar [Schätzen]!".

36 | Cad. Nietzsche, Guarulhos/Porto Seguro, v.40, n.2, p. 33-51, maio/agosto, 2019. 
procedimento de introdução: "Nossos valores são introduzidos por interpretação [hineininterpretirt] nas coisas" (Nachlass/FP 18851886, 2[77], KSA 12.97). A noção de perspectiva, por sua vez, indica que todo processo interpretativo de introdução de valor tem uma determinada proveniência: "Em toda estimativa de valor se trata de uma determinada perspectiva: conservação do indivíduo, de uma comunidade, de uma raça, de um Estado, de uma igreja, de uma crença, de uma cultura" (Nachlass/FP 1884, 26 [119], KSA 11.181).

As estimativas de valor são, por conseguinte, múltiplas. De um lado, a mesma coisa pode ser objeto de avaliações distintas: o que um povo considera bom, declara Nietzsche em Assim falava Zaratustra, é passível de ser visto como desprezível por outro (ZA/ ZA I, Dos mil e um alvos, KSA 4.74). De outro lado, a mesma palavra empregada para designar um determinado valor pode abrigar sentidos diversos, mesmo contrários, conforme a perspectiva avaliadora. $\mathrm{Na}$ ótica da moral nobre, o valor "bom", por exemplo, não possui o mesmo significado que o valor "bom" segundo a moral escrava. De acordo com a primeira dissertação de Para a genealogia da moral, a divergência entre essas duas perspectivas é tal, que o "mau", na visão da moral do ressentimento, não é senão o "bom" da moral nobre reinterpretado pelos impotentes (GM/GM I, 11, KSA 5.274)

Assim como as avaliações são múltiplas, não existe uma hierarquia em si dos valores, pois a hierarquização também depende da perspectiva avaliadora. Por isso, a pergunta pelo valor dos valores aplica-se tanto à instituição dos valores quanto à sua hierarquização ${ }^{6}$. Consideremos, por exemplo, os valores de "verdade" e de "erro".

\footnotetext{
5 Sobre a importância da distinção entre as perspectivas avaliadoras e sobre a questão do valor dos valores, ver o capítulo "O procedimento genealógico. Vida e valor", em Nietzsche, das forças cósmicas aos valores humanos, de Scarlett Marton (2010, pp. 81-107). Nessa obra, a autora defende a ideia de que os valores supõem avaliações, as quais, por sua vez, supõem valores (pp. 86 e seguintes). Levando em conta essa lógica, a genealogia pretende avaliar o valor dos valores e, para tanto, toma por critério a vida (pp. 102 e seguintes).

6 Sobre o problema do valor dos valores, ver GM/GM, Prefácio, 3 e 6, KSA 5.249-250 e 252-253.
} 
Corbanezi, E.

Conforme uma determinada perspectiva avaliadora, interpreta-se "a verdade" como algo dado e absoluto, universal e necessário, uno e imutável, desinteressado e benéfico, enquanto se vincula o "erro" ao transitório, ao sensível, ao prejudicial e, numa palavra, a tudo que se deve evitar a qualquer custo. Então, sempre conforme a mesma ótica avaliadora, procede-se à hierarquização desses valores, o que em alguns casos quer dizer não só preferir a verdade ao erro, mas conferir à verdade valor em si. A filosofia de Nietzsche, entretanto, questiona esse modo de estimar e de hierarquizar os valores: aquilo que se denominou verdade, sustenta ele, nada mais é do que uma espécie de erros - a espécie de erros de que dependem determinadas formas de vida. Assim, Nietzsche afirma que o erro é uma condição vital $^{7}$.

Múltiplas, as estimativas de valor são sintomas de diferentes modos de vida: "As estimativas de valor estão necessariamente relacionadas de alguma maneira às condições de existência", assegura Nietzsche, advertindo em seguida, porém, que nem por isso "elas [as estimativas de valor] seriam verdadeiras, ou seriam precisas" (Nachlass/FP 1885, 34[247], KSA 11.503) ${ }^{8}$. As estimativas de valor constituem sintomas de "condições de existência" ao menos de duas maneiras, conforme o sentido que se atribui a essa expressão.

Parece-nos que "condição", em seu primeiro sentido, quer dizer "exigência". Nesse caso, as estimativas de valor traduzem as exigências necessárias para que um determinado modo de vida se conserve e/ou cresça9 ${ }^{9}$ Todavia, um modo de estimar valores não se livra da crítica de Nietzsche pelo simples fato de conservar

7 Ver o Nachlass/FP 1885, 38[4], KSA 11.598.

8 Ver também o Nachlass/FP 1884, 26[45], KSA 11.159.

9 Sobre as estimativas de valor consideradas como condições de conservação e/ou de crescimento e intensificação da vida enquanto vontade de potência, ver Nachlass/FP 1887, 9[38], KSA 12.352 e 9[39], KSA 12.353, assim como Nachlass/FP 1888, 11[73], KSA 13.36 e 11[96], KSA 13.45. Visto que vida é vontade de potência, seu crescimento e sua intensificação não implicam necessariamente sua conservação; daí a fórmula "e/ou" empregada acima. Retornaremos a esse tema mais adiante.

38 | Cad. Nietzsche, Guarulhos/Porto Seguro, v.40, n.2, p. 33-51, maio/agosto, 2019. 
um determinado modo de vida, já que pode preservar uma forma de vida indesejável. Ademais, um modo de estimar valores não é necessariamente verdadeiro apenas por favorecer a conservação: "A vida não é argumento; entre as condições da vida poderia estar o erro", já havia afirmado Nietzsche em A gaia ciência. (FW/GC 121, KSA 3.477-478, trad. RRFT) ${ }^{10}$.

Ademais, se todas as estimativas de valor, embora não verdadeiras, fossem pelo menos "precisas" (Nachlass/FP 1885, 34[247], KSA 11.503), então elas traduziriam necessariamente as exigências de conservação e/ou de intensificação de uma determinada forma de vida: assim, em princípio, bastaria que um modo de vida estimasse valores para garantir sua conservação e/ou seu crescimento. No entanto, embora viver consista em estimar valores, nem toda estimativa de valor assegura a mera conservação ou o crescimento.

Tais riscos de fracasso explicam-se, em primeiro lugar, pela relação mesma entre as noções de vida, de avaliação e de vontade de potência. Uma vez que em toda avaliação se exprime vontade de potência e que existem casos nos quais os seres vivos valorizam mais outras coisas do que a própria conservação, acontece de a vida, em dadas circunstâncias, sacrificar-se por potência ${ }^{11}$. Mas existe ainda uma segunda razão pela qual um modo de avaliar pode levar ao perecimento. Determinados erros podem, decerto, conservar a vida; outros há, todavia, que bem podem destruí-la. Com efeito, sustenta Nietzsche no quinto livro de $A$ gaia ciência, visto não dispormos de um órgão para conhecer a verdade, o que estimamos ser útil pode revelar-se, na realidade, simples crença que nos expõe à ruína (FW/GC

10 Nietzsche continuará a insistir nessa ideia: o fato de que a vida do homem possa, por exemplo, depender da lei da causalidade nada prova a respeito da verdade desta última (Nachlass/FP 1884, 26[12], KSA 11.152-153). Ver também o terceiro e o quarto parágrafos de Para além de bem e mal (KSA 5.17-18).

11 Além da passagem já evocada de Assim falava Zaratustra (ZA/ZA II, Da superação de si, KSA 4.148), ver FW/GC 349, KSA 3.585-586. 
Corbanezi, E.

354, KSA 3.593). As estimativas de valor constituem, portanto, uma condição necessária, mas não suficiente para a conservação da vida.

Se um modo de estimar valores não preserva a existência, então ele não traduz "condições de vida" entendidas, conforme aquele primeiro sentido de que falamos há pouco, como exigências necessárias e suficientes para a conservação. Ainda assim, tal modo de estimar valores continua a refletir "condições de vida", mas agora num segundo sentido, meramente circunstancial: ele revela como vive uma determinada forma de vida. Portanto, todas as estimativas de valor constituem sempre, pelo menos, signos que apontam para a maneira de ser de certas formas de vida, sejam estas destinadas a sucumbir, a conservar-se ou a crescer.

\section{IV.}

Viver, já dissemos, consiste em estimar valores, e as estimativas de valor, por sua vez, referem-se a formas de vida particulares. Mas é preciso acrescentar que toda maneira de estimar valores traduz, de algum modo, a afirmação de uma forma de existência e, por conseguinte, a negação de outras. É o que se depreende de um fragmento póstumo no qual Nietzsche anota: "Sem um determinado ponto de vista, não se pode falar sobre o valor de nenhuma coisa: i.e., uma determinada afirmação de uma determinada vida é o pressuposto de todo estimar [Schätzens]" (Nachlass/FP 1884, 26[55], KSA 11.162). No entanto, ainda que viver equivalha a avaliar e que as avaliações representem a afirmação de um modo de vida e a negação de outros, Nietzsche sustenta já em Humano, demasiado humano que todas as nossas "avaliações [Schätzungen]" são necessariamente injustas e que, portanto, todos os juízos sobre o valor da vida também resultam ilógicos e injustos (MA I/HH I 32, KSA 2.51, trad. PCS).

Tal posição conserva-se em escritos posteriores. No prefácio redigido em 1886 para a segunda edição de Humano, demasiado

40| Cad. Nietzsche, Guarulhos/Porto Seguro, v.40, n.2, p. 33-51, maio/agosto, 2019. 
humano, após assinalar "o perspectivístico de toda estimativa de valor", Nietzsche afirma "a injustiça necessária de todo pró e contra, a injustiça como indissociável da vida, a vida mesma como condicionada pelo perspectivístico e sua injustiça" (MA I/HH I, Prefácio, 6, KSA 2.20 , trad. RRTF). Com efeito, o caráter perspectivístico e injusto das avaliações constitui uma condição de vida e, ao mesmo tempo, um obstáculo insuperável para uma apreciação justa e verdadeira do valor da vida. Se Nietzsche reafirma a "necessidade de ser injusto", para lembrar o título do parágrafo 32 de Humano, demasiado humano, ele evidencia em seus textos ulteriores a função sintomatológica dos “juízos sobre o valor da vida" (MA I/HH I 32, KSA 2.51, trad. PCS). Tendo asseverado, em Crepúsculo dos ídolos, que "o valor da vida não pode ser avaliado" e que, por conseguinte, "juízos de valor sobre a vida, pró ou contra, nunca podem, em definitivo, ser verdadeiros", o filósofo acrescenta que semelhantes apreciações "só têm valor como sintomas, só como sintomas entram em consideração" (GD/CI, $O$ problema de Sócrates 2, KSA 6.68, trad. RRFT) $)^{12}$.

Mas como funcionaria tal sintomatologia? Também nos casos de juízos de valor sobre a vida, trata-se de avaliar o valor dos valores, quer dizer, de analisá-los à luz das interrogações já formuladas por Nietzsche no Prefácio de Para a genealogia da moral: "Obstruíram ou favoreceram até agora o prosperar da humanidade? São um signo de estado de indigência, de empobrecimento, de degeneração da vida? ou, inversamente, denuncia-se neles a plenitude, a força, a vontade de vida, seu ânimo, sua confiança, seu futuro?" (GM/GM, Prefácio 3, KSA 5.250, trad. RRTF) ${ }^{13}$.

12 Ver também FW/GC, Prefácio da segunda edição, 2, KSA 3.348-349.

13 Ver também (GM/GM, Prefácio 6, KSA 5.253). Sobre a relação entre valores e modos de vida, ver "Préface. - Le sens de la référence à l'avenir" e "La culture comme problème. - La redétermination nietzschéenne du questionnement philosophique", em "Oui, l'homme fut un essai". La philosophie de l'avenir selon Nietzsche, de Patrick Wotling (2016). Wotling distingue dois significados da noção de valor. Em seu primeiro sentido, "valores (Werthe)" ou "avaliações (Werthschätzungen)" designam "uma série de preferências fundamentais não refletidas" (p. 31) que "condiciona [...] toda atividade humana" (p. 13); eles "são fontes da organização da vida sob formas particulares e diferenciadas" 
Corbanezi, E.

Os juízos de valor sobre a vida não se exprimem somente por um "sim" ou um "não" explícito a respeito da vida; toda maneira de estimar valores traduz, de algum modo, a afirmação de uma forma determinada de existência e, por conseguinte, a negação de outras. Dito de outro modo, não se trata de proferir um "sim" ou um "não" à vida em geral, mas de afirmar uma forma de existência $e$ de negar outras. E é precisamente a afirmação e a negação de formas de vida determinadas que Nietzsche considera como sintomas de uma vida ascendente ou decadente. Assim, o procedimento nietzschiano de avaliação das estimativas de valor não pode prescindir de uma certa concepção de vida, isto é, de uma certa interpretação a respeito do que seja a vida. De fato, ao avaliar o valor das estimativas de valor, Nietzsche procura identificar se um determinado modo de estimar valores afirma ou nega a sua própria (a de Nietzsche) concepção de vida. $\mathrm{O}$ critério do filósofo pressupõe, pois, uma decisão: as estimativas de valor que afirmam a concepção nietzschiana de vida ascendente são estimadas superiores àquelas que a negam - as primeiras qualificamse como ascendentes; as últimas, como decadentes.

Esse procedimento está em operação, parece-nos, justamente nos dois capítulos de Crepúsculo dos ídolos em que, sustentando que os juízos de valor sobre a vida entram em consideração apenas como sintomas de formas de vida, Nietzsche procura mostrar, respectivamente em $O$ problema de Sócrates e em Moral como contranatureza, que o modo de valorar dos reputados "mais sábios" e o modo cristão de valorar são sintomas de uma vida decadente.

No capítulo $O$ problema de Sócrates, Nietzsche sustenta que os mais sábios sempre julgaram, no fundo, que a vida "não vale

(p. 12). Em seu segundo sentido, "valor" denota a apreciação da "incidência nociva ou benéfica" desses valores (no primeiro sentido) relativamente à vida (pp. 68 e 69). Na Introduction aos Éléments pour la généalogie de la morale (pp. 30 e 31), sua tradução de Para a genealogia da moral, e numa nota (p. 56), Wotling mostra que Nietzsche faz operar os dois sentidos mencionados do termo "valor" ao formular a exigência genealógica de pôr em questão "o próprio valor desses valores" (GM/GM, Prefácio 6, KSA 5.253, trad. PCS). Nessa passagem, o termo "valor", em sua primeira ocorrência, tem o segundo sentido indicado acima, enquanto em sua segunda ocorrência possui o primeiro sentido. 
nada" e, por isso, revelam-se todos decadentes (GD/CI, O problema de Sócrates 1, KSA 6.67, trad. PCS). Como assinala já o título do capítulo, a análise ali empreendida tem por objeto sobretudo a figura de Sócrates, considerada paradigmática na medida em que representa o caso extremo de uma situação geral de degenerescência entre os atenienses (GD/CI, O problema de Sócrates 9, KSA 6.71). Indícios de decadência em Sócrates são não apenas a anarquia dos instintos, confessada por ele próprio, mas também "a superfetação do lógico" (GD/CI, O problema de Sócrates 4, KSA 6.69, trad. PCS). Para relacionar esses dois elementos, Nietzsche evoca, no terceiro e no nono parágrafos do capítulo, tanto o testemunho do "fisiognomonista" Zópiro a respeito de Sócrates como a maneira pela qual este último reage (GD/CI, O problema de Sócrates 9, KSA 6.71). No entender de Zópiro, a face de Sócrates revelava que ele "abrigava todos os vícios e apetites ruins" (GD/CI, O problema de Sócrates 3, KSA 6.69, trad. PCS). Admitindo o julgamento de seu interlocutor, Sócrates responde-lhe, entretanto, com a afirmação de que dominara tais vícios e apetites (GD/CI, O problema de Sócrates 9 , KSA 6.71) por meio da "racionalidade a todo preço" (GD/CI, O problema de Sócrates 11, KSA 6.73, trad. RRTF).

O meio utilizado por Sócrates, que não é mais do que "seu artifício pessoal de autoconservação", aparece aos olhos de todos, entretanto, como solução universal (GD/CI, O problema de Sócrates 11, KSA 6.73, trad. RRTF). É o que atesta, segundo Nietzsche, a filosofia grega a partir de Platão, que equipara razão, virtude e felicidade, assim como, aos "desejos obscuros", opõe "a luz diurna da razão" (GD/CI, O problema de Sócrates 10, KSA 6.72, trad. PCS). É certo que, para Nietzsche, tanto a anarquia como a tirania dos instintos constituem indícios de decadência; não menos certo, porém, é que o meio tomado por salvador, isto é, a tirania da racionalidade, consiste igualmente numa "expressão de décadence" (GD/CI, O problema de Sócrates 11, KSA 6.72, trad. RRTF). Com efeito, assim como não se 
Corbanezi, E.

deve permitir a tirania dos instintos, não se deve preconizar a tirania da razão, a fortiori porque receitar a racionalidade a todo preço implica interditar "toda concessão aos instintos" (GD/CI, O problema de Sócrates 10, KSA 6.72, trad. PCS). Ora, uma proibição assim generalizada supõe a possibilidade de uma vida sem instintos, o que, para Nietzsche, é inconcebível. E ainda que se mostrasse possível, tal proibição seria alvo de crítica, já que teria por consequência necessária a interdição dos instintos dos quais depende a vida tal como Nietzsche a concebe.

O autor de Crepúsculo dos ídolos não pretende combater absolutamente nem a razão nem os instintos, mas apenas a situação de tirania ou de anarquia em que eles podem encontrar-se. É assim que Nietzsche pode opor sua própria concepção de vida àquela de Sócrates e de seus sucessores. Se, no entender destes últimos, "toda concessão aos instintos, ao inconsciente, leva para baixo" (GD/CI, $O$ problema de Sócrates 10, KSA 6.72, trad. PCS), Nietzsche, por sua vez, afirma: "Ter de combater os instintos - eis a fórmula para a décadence: enquanto a vida ascende, felicidade é igual a instinto" (GD/CI, O problema de Sócrates 11, KSA 6.73, trad. RRTF modificada). Proibindo qualquer concessão aos instintos em nome de uma racionalidade a todo preço, Sócrates e seus seguidores negam a vida - ou, ao menos, negam o que, segundo a apreciação de Nietzsche, constitui uma vida ascendente. Como os juízos de valor sobre a vida entram em consideração apenas como sintomas, Nietzsche conclui que, ao negarem a vida - ou, mais precisamente, a concepção nietzschiana de vida ascendente -, tais "sábios" são, em realidade, decadentes.

No capítulo Moral como contranatureza, por seu turno, Nietzsche assegura que quase toda moral existente se voltou "contra os instintos da vida" (GD/CI, Moral como contranatureza 4, KSA 6.85, trad. PCS). Nesse contexto, ele toma como caso paradigmático a moral cristã. Ao visar à aniquilação e à castração das paixões e dos desejos, "a prática da Igreja é hostil à vida", pois "atacar as paixões pela raiz 
significa atacar a vida pela raiz" (GD/CI, Moral como contranatureza 1, KSA 6.83, trad. PCS). A prática da Igreja se opõe à vida não apenas porque vê nas paixões um inimigo e faz guerra contra ele, mas sobretudo em função do modo como combate seus adversários, ou seja, visando a aniquilá-los: "Em todos os tempos a Igreja quis a destruição de seus inimigos" (GD/CI, Moral como contranatureza 3, KSA 6.84, trad. PCS).

Aquilo que Nietzsche denomina "espiritualização da inimizade" significa então uma vitória sobre o cristianismo (GD/CI, Moral como contranatureza 3, KSA 6.84, trad. PCS). Contrariamente à prática da Igreja, tal espiritualização consiste em valorizar inimizades e antagonismos em grande número. Semelhante ideia, bem se vê, está em harmonia com o caráter dinâmico da vida concebida como vontade de potência que se supera a si mesma defrontando-se com resistências e triunfando sobre elas. Nietzsche, portanto, não se opõe à guerra em si, uma vez que, em seu entender, "renunciamos à vida grande, se renunciamos à guerra" (GD/CI, Moral como contranatureza 3 , KSA 6.84, trad. PCS). De fato, conforme já mencionado, sua crítica dirige-se mais precisamente a um certo modo de fazer guerra, isto é, àquela forma de combater em que se procura aniquilar o inimigo.

Sem espiritualizar a hostilidade, a Igreja não poderia, por conseguinte, espiritualizar a sensualidade, percebida como uma espécie de inimiga: "Ela jamais pergunta: 'Como espiritualizar, embelezar, divinizar um desejo?' - em todas as épocas, ao disciplinar, ela pôs a ênfase na erradicação (da sensualidade, do orgulho, da avidez de domínio [Herrschsucht], da cupidez [Habsucht], da ânsia de vingança)" (GD/CI, Moral como contranatureza 1 , KSA 6.83, trad. PCS). A moral cristã é, pois, hostil à vida não só em razão de seu elemento aniquilador, mas também porque ela se volta "contra os 
Corbanezi, E.

instintos da vida" tal como Nietzsche a compreende (GD/CI, Moral como contranatureza 4, KSA 6.85, trad. PCS) ${ }^{14}$.

A partir desse ponto, o filósofo dá sequência à sua reflexão utilizando um procedimento análogo ao adotado no capítulo $O$

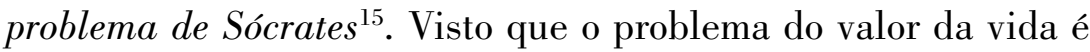
inacessível, aquela “condenação da vida” só entra em consideração enquanto "sintoma de uma determinada espécie de vida". Como é sempre a vida, ou mais exatamente, um determinado modo de vida, que estabelece valores, é preciso então descobrir qual tipo de existência estima valores na moral cristã:

[...] A vida mesma valora através de nós, quando instituímos valores... Disto se segue que também essa contranatureza de moral, que capta Deus como contraconceito e condenação da vida, é apenas um juízo de valor da vida - de que vida? De que espécie de vida? - Mas eu já dei a resposta: da vida declinante, da vida enfraquecida, cansada, condenada. Moral, como foi entendida até agora [...] - é o próprio instinto de décadence, que faz de si um imperativo: ela diz: 'pereça!'. (GD/CI, Moral como contranatureza 5, KSA 6.86, trad. RRTF modificada).

V.

Se a noção de vida desempenha o papel de critério na sintomatologia de Nietzsche, seus escritos oferecem indicações de que tal procedimento depende de uma interpretação perspectivística a respeito do que é a vida. Após afirmar que, para avaliar o valor das estimativas de valor, é preciso tomar por referência a vida, ele

14 No entender de Nietzsche, com efeito, em vez de aspirar à supressão, por exemplo, da avidez de domínio (Herrschsucht) e da cupidez (Habsucht), seria preciso intensificá-las, quando se quer intensificar a vida (ver JGB/BM 23, KSA 5.38). Voltaremos a esse ponto adiante.

15 Indicar aspectos comuns aos procedimentos de Nietzsche nos capítulos $O$ problema de Sócrates e Moral como contranatureza não equivale a negar suas respectivas particularidades. Sobre as diferentes relações entre os conceitos de vida e de valor na formulação do critério de avaliação das avaliações nos dois capítulos mencionados, ver Scarlett Marton, 2014, pp. 321-342. Quanto ao problema dos juízos de valor sobre a vida, ver também Müller-Lauter, 1999, pp. 244-250.

46 | Cad. Nietzsche, Guarulhos/Porto Seguro, v.40, n.2, p. 33-51, maio/agosto, 2019. 
pergunta: "Mas o que é vida?". E em seguida responde: "Aqui se faz necessária uma nova e mais determinada versão do conceito 'vida': minha fórmula para isso diz: vida é vontade de potência" (Nachlass/ FP 1885-1886, 2[190], KSA 12.161).

Formulada de maneira dogmática, a pergunta "o que é isto?" pretende obter uma resposta que revele a essência do objeto em questão. No entanto, Nietzsche sublinha que "a 'essência' [...] é algo perspectivístico" (Nachlass/FP 1885-1886, 2[149] KSA 12.140). Com efeito, o caráter perspectivístico já pertence à própria pergunta "o que é isto?": "No fundo, trata-se sempre de 'o que é isto para mim?' (para nós, para tudo o que vive etc.)" (Nachlass/FP 1885-1886, 2[149] KSA 12.140). Ora, é precisamente esse caráter perspectivístico que se acha dissimulado na formulação dogmática tanto da pergunta "o que é isto?" como de sua resposta, que se pretendem impessoais e incondicionadas.

Nietzsche, contudo, procede de outro modo. Uma vez formulada a pergunta "o que é vida?", ele introduz sua resposta, segundo a qual "vida é vontade de potência", precisando que se trata aí de "minha fórmula". Dessa maneira, o filósofo indica o caráter necessariamente perspectivístico da resposta e ao mesmo tempo da pergunta, ainda que ele próprio, ao formular a sua concepção de vida, nem sempre explicite esse caráter perspectivístico e sugira com frequência até mesmo o contrário, propondo-se a determinar "a essência da vida" (GM/GM II, 12, KSA 5.316, trad. RRTF) ${ }^{16}$.

Perspectivística, a concepção nietzschiana de vida como vontade de potência encerra estimativas de valor. É o que se pode depreender, por exemplo, de passagens de Para além de bem e mal sobre a vida. No início do primeiro capítulo desse livro, Nietzsche

16 Ver também GM/GM III, 27, KSA 5.410. Em Para além de bem e mal, Nietzsche já havia sublinhado: "Aqui devemos pensar radicalmente até o fundo, e guardarmo-nos de toda fraqueza sentimental: a vida mesma é essencialmente apropriação, ofensa, sujeição do que é estranho e mais fraco, opressão, dureza, imposição de formas próprias, incorporação e, no mínimo e mais comedido, exploração [...]" (JGB/BM 259, KSA 5.207). 
Corbanezi, E.

afirma que a falsidade de um juízo não constitui, por si só, uma objeção, pois o que se deve perguntar é em que medida ele promove ou não a vida (JGB/BM 4, KSA 5.18). Algumas páginas adiante, o autor menciona a sua concepção de vida como vontade de potência (JGB/BM 13, KSA 5.27) e, no último parágrafo do capítulo, precisa o que é necessário intensificar para intensificar a vida, mostrando-se consciente do mal-estar que a sua posição pode provocar:

Supondo, porém, que alguém tome os afetos de ódio, inveja, cupidez [Habsucht], ânsia de domínio [Herrschsucht], como afetos que condicionam a vida, como algo que tem de estar presente, por princípio e de modo essencial, na economia global da vida, e em consequência deve ser realçado, se a vida é para ser realçada - esse alguém sofrerá com tal orientação de seu julgamento como quem sofre de enjoo do mar. (JGB/BM 23, KSA 5.38 , trad. PCS).

A avaliação do valor dos valores adota por critério a vida entendida como vontade de potência ou, como precisa Nietzsche, a vontade de potência em forma de vida ascendente ${ }^{17}$. Em outros termos: ao avaliar o valor das avaliações, o filósofo procura identificar se elas afirmam ou negam a sua própria concepção de vida ascendente: no primeiro caso, ele as considera como sintoma de vida ascendente; no segundo, como sintoma de vida decadente.

Se, porém, essa sintomatologia funciona tal como a descrevemos, ela suscita ainda uma última observação. Ainda que não se possa avaliar o valor da vida, aquele que avalia o valor dos valores adotando por critério a vida tem de fazê-lo a partir de uma determinada concepção de vida - concepção que afirma uma forma de existência em detrimento de outras, que reconhece a superioridade de certos valores em comparação com outros, que encerra assim avaliações perspectivísticas e, portanto, injustas. Ora, não sendo absoluta, mas antes provindo de uma determinada perspectiva, a

17 Ver o Nachlass/FP 1888, 16[86], KSA 13.516.

48 | Cad. Nietzsche, Guarulhos/Porto Seguro, v.40, n.2, p. 33-51, maio/agosto, 2019. 
concepção nietzschiana de vida ascendente, empregada como critério, implica inexoravelmente avaliações; dito com outras palavras: seu critério de avaliação do valor dos valores encerra, também ele, valores. Se, entretanto, de acordo com o próprio Nietzsche, todos os valores dependem de avaliações perspectivísticas e se estas são necessariamente injustas - razão pela qual os juízos sobre o valor da vida valem apenas como sintomas -, então uma conclusão nos parece inevitável: tal critério não pode estar isento de toda injustiça.

\title{
Symptomatology and Philosophy of
} Affirmation in Nietzsche

\begin{abstract}
The association of notions of life, value and will to power established in Nietzsche's Thus Spoke Zarathustra reveals a great amount of consequences to the author's philosophy. In this paper we propose to investigate how these concepts constitute a necessary condition for the Nietzschean symptomatology, which is a procedure that evaluates the value of the values, considering them as signs of an ascending or declining life. Furthermore, we attempt to demonstrate that the values may solely be regarded as superior and ascending if they translate an affirmation of the Nietzschean conception of ascending life. Finally, this study will support the idea that the criterion to evaluate the values itself implies other values, which renders it unjust.
\end{abstract}

Keywords: symptomatology, life, will to power, value, criterion 
Corbanezi, E.

\section{Referências bibliográficas}

MARTON, S. Nietzsche: das forças cósmicas aos valores humanos. 3. ed. Belo Horizonte: Editora UFMG, 2010.

. À la recherche d'un critère d'évaluation des évaluations. Les notions de vie et de valeur chez Nietzsche. In: Denat, C.; WOTLING, P. Les hétérodoxies de Nietzsche. Lectures du Crépuscule des idoles. Reims: Éditions et presses universitaires de Reims, 2014, p. 321-342.

MÜLLER-LAUTER, W. Über Freiheit und Chaos. Berlim/NovaYork: Walter de Gruyter, 1999.

NIETZSCHE, F. Sämtliche Werke. Kritische Studienausgabe (KSA), 15 vols. (Organizada por Giorgio Colli e Mazzino Montinari). Munique: Walter de Gruyter, 1999.

. Friedrich Nietzsche: Obras incompletas. Trad. Rubens Rodrigues Torres Filho. São Paulo: Editora Nova Cultural, 2000.

. Humano, demasiado Humano: um livro para espíritos livres. Trad. Paulo César de Souza. São Paulo: Companhia das Letras, 2000

- Aurora: Reflexões sobre os Preconceitos Morais. Trad. Paulo César de Souza. São Paulo: Companhia das Letras, 2004.

. A gaia Ciência. Trad. Paulo César de Souza. São Paulo: Companhia das Letras, 2001.

- Assim falou Zaratustra: um Livro para todos e para ninguém. Trad. Paulo César de Souza. São Paulo: Companhia das Letras, 2011.

. Além do Bem e do Mal: Prelúdio a uma Filosofia do Futuro. Trad. Paulo César de Souza. São Paulo: Companhia das Letras, 2005.

. Genealogia da Moral: uma Polêmica. Trad. Paulo César de Souza. São Paulo: Companhia das Letras, 1998.

. Éléments pour la généalogie de la morale. Trad. P. Wotling. Paris: Librairie Générale Française, 2000.

$50 \mid$ Cad. Nietzsche, Guarulhos/Porto Seguro, v.40, n.2, p. 33-51, maio/agosto, 2019. 
. Crepúsculo dos Ídolos, ou, Como se Filosofa com o Martelo. Trad. Paulo César de Souza. São Paulo: Companhia das Letras, 2006.

WOTLING, P. “Oui, l'homme fut un essai”. La philosophie de l'avenir selon Nietzsche. Paris: PUF, 2016. 